\title{
Avaliação nutricional da silagem de grãos úmidos de sorgo de alto ou de baixo conteúdo de tanino para frangos de corte ${ }^{1}$
}

\author{
Livia Carla Grigoletto Barcellos ${ }^{2}$, Antonio Claudio Furlan ${ }^{3}$, Alice Eiko Murakami ${ }^{3}$, Marcos \\ Augusto Alves da Silva ${ }^{2}$, Ronaldo Martins da Silva ${ }^{4}$
}

\footnotetext{
1 Parte da Dissertação de Mestrado da primeira autora.

2 Pós-Graduação em Zootecnia - DZO - UEM - Maringá - PR.

${ }^{3}$ Departamento de Zootecnia - UEM - Maringá - PR.

4 Graduação em Zootecnia - UEM - Maringá - PR.
}

RESUMO - Foram realizados dois experimentos com o objetivo de avaliar a utilização da silagem de grãos úmidos de sorgo (SGUS) de alto ou baixo conteúdo de tanino na alimentação de frangos de corte. No ensaio de digestibilidade, foram utilizadas 90 aves de 20 dias de idade, distribuídas em um delineamento experimental inteiramente casualizado, com três tratamentos, seis repetições e cinco aves por unidade experimental. Os valores de matéria seca (MSM), matéria orgânica (MOM), proteína (PM), amido (AMM) e energia metabolizáveis (EM) na matéria natural $(66,22 \%$ de MS para a SGUS de alto tanino e $65,28 \%$ para a SGUS de baixo tanino) foram, respectivamente, de 57,$29 ; 56,96 ; 4,45 ; 35,27 \%$ e $2.408 \mathrm{kcal} / \mathrm{kg}$ para a SGUS de alto tanino e de 60,$42 ; 59,95 ; 5,11 ; 39,58 \%$; e $2.578 \mathrm{kcal} / \mathrm{kg}$ para a SGUS de baixo tanino. No ensaio de desempenho, foram utilizados 840 pintos de um dia de idade, distribuídos em um delineamento inteiramente casualizado, com sete tratamentos, quatro repetições e trinta aves por unidade experimental. Os tratamentos consistiram de uma ração à base de milho e farelo de soja e de seis rações com 33, 66 e 100\% de substituição do milho por SGUS de alto ou baixo tanino. A inclusão de níveis crescentes de SGUS com alto tanino piorou linearmente o peso vivo, o consumo de ração, o ganho de peso e a conversão alimentar aos 40 dias de idade, não se observando o mesmo efeito para a SGUS de baixo tanino. As aves que receberam ração com SGUS de alto tanino nos níveis de 66 e 100\% de substituição apresentaram, aos 40 dias de idade, menor peso vivo e ganho de peso. Observou-se decréscimo linear na coloração da perna das aves com a inclusão de SGUS nas rações. A silagem de grão úmido de sorgo de alto tanino pode substituir até $33 \%$ e a de baixo tanino, até $100 \%$ do milho em rações para frangos de corte, sem prejudicar o desempenho e proporcionando menor custo por quilograma de frango produzido.

Palavras-chave: desempenho, digestibilidade, frangos de corte, sorgo, valor energético

\section{Nutritional evaluation of high moisture sorghum silage grain with high or low tannin content for broilers}

\begin{abstract}
Two trials were carried out to evaluate the moisture sorghum silage (HMSS) with high or low tannin content as ingredient in broiler chicken diets. In the digestibility trial, ninety 20-d chicks were assigned to a completely randomized design with three treatments and six replications, and five chicks per experimental unit. Coefficients of metabolizable dry matter (MDM), metabolizable protein (MP), metabolizable starch (MS), metabolizable organic matter (MOM) and metabolizable energy (ME) of HMSS with high tannin, as-fed basis $(66.22 \% \mathrm{DM})$, were as follows: $57.29 ; 56.96 ; 4.45 ; 35.27 \%$ and $2,408 \mathrm{kcal} / \mathrm{kg}$, respectively. The coefficients of HMSS with low tannin were of $60.42 ; 59.95 ; 5.11 ; 39.58 \%$ and $2578 \mathrm{kcal} / \mathrm{kg}$, respectively, as-fed basis $(65.28 \% \mathrm{DM})$. In the performance assay, eight hundred and forty chicks were assigned to a completely randomized experimental design, with seven treatments, four replications and thirty chicks per experimental unit. Treatments consisted of a corn-soybean meal -based diet and six with 33, 66 and 100\% HMSS with high or low content replaced by dry corn. Increasing HMSS levels with high tannin contents in diets caused a linear decrease on weight, weight gain, feed intake at 21 and 40 days old, but this effect was not observed for HMSS of low tannin content. Forty-day-old broilers fed diets with HMSS of high tannin content in 66 and 100\% replacement levels showed lower weight and lower weigh gain. However, broilers fed HMSS with low tannin content did not differ from control. Linear decrease on the chicken leg color of was observed when HMSS was included in the diets. Performance results demonstrated that HMSS with high tannin content may replace um $33 \%$ of corn and with low tannin HMSS up to $100 \%$ of corn in diets of broilers, with no effect on performance and with lower cost per kilogram of produced broiler.
\end{abstract}

Key Words: broilers, digestibility, energetic values, performance, sorghum 


\section{Introdução}

A ocorrência de produção limitada de milho e de políticas reguladoras de estoque, entre outros fatores, em determinados anos, tem levado diversos produtores ao uso de ingredientes alternativos na alimentação animal.

A utilização de silagem de grãos úmidos de milho na alimentação de frangos de corte consiste em mais uma opção para redução dos custos de produção, uma vez que esse alimento apresenta uma série de vantagens, como conservação e estocagem em silos e antecipação na colheita em três a quatro semanas, permitindo a implantação de outra cultura na área, maximizando o uso da terra e reduzindo as perdas econômicas (Costa et al., 1999).

Os poucos trabalhos realizados com silagem de grãos úmidos de milho para frangos de corte (Martins et al., 2000; Carrijo et al., 2000; Sartori et al., 2002) apresentam certa discrepância em seus resultados. Martins et al. (2000) observaram efeito redutor no peso final de frangos de corte aos 42 dias de idade, ao substituírem 100\% do milho seco por silagem de grãos úmidos de milho na ração. Sartori et al. (2002), no entanto, afirmam que a silagem de grãos úmidos de milho pode substituir totalmente o milho seco em dietas para frangos de corte de até 21 dias de idade.

A utilização de sorgo como substituto do milho em rações para animais, sobretudo os não-ruminantes, vem sendo estudada há vários anos no Brasil, pois este cereal apresenta ótima adaptabilidade aos diversos tipos de solos e climas brasileiros.

O sorgo apresenta nível de proteína bruta um pouco superior ao do milho (Rostagno et al., 2000), além de alta variabilidade da $\mathrm{PB}$, dependendo das variedades, do ambiente e da fertilidade do solo (Scheuermann, 1998), podendo ser considerado equivalente ao milho em minerais e vitaminas. É pobre em substâncias pigmentantes e pode conter, conforme a variedade, compostos fenólicos como o tanino, que tem ação antinutricional.

Teeter et al. (1986) afirmam que a incubação anaeróbica do sorgo com alto teor de umidade tem sido utilizada para minimizar o tanino quimicamente detectável, que, segundo Van Soest (1994), pode ser hidrolisado para açúcares em meio ácido, podendo-se deduzir que a acidez da silagem exerce importante papel na digestão de grãos de sorgo com alto teor de tanino, melhorando o desempenho animal (Mitaru et al., 1984a).

Como a utilização do grão de sorgo seco pode trazer algumas desvantagens em termos de desempenho, pela presença do tanino, a ensilagem pode ser uma alternativa para se reduzir o tanino do grão e melhorar o desempenho dos animais. Garcia et al. (1995) afirmam que a combinação da moagem com o armazenamento do grão de sorgo, por curto período de tempo, pode reduzir o teor de tanino, promovendo melhor desempenho de pintos de corte.

Considerando o aumento da produção de sorgo nas propriedades agrícolas brasileiras e a escassez e informações sobre a utilização da silagem de grãos úmidos na alimentação animal, justifica-se a realização de estudos para avaliação do desempenho de frangos de corte alimentados com silagem de grãos úmidos de sorgo.

O objetivo neste trabalho foi avaliar, por meio de ensaios de digestibilidade e experimento de desempenho, o uso da silagem de grãos úmidos de sorgo, de alto ou baixo conteúdo de tanino, em substituição ao milho seco em rações para frangos de corte.

\section{Material e Métodos}

As silagens utilizadas nas rações foram confeccionadas apenas com os grãos de sorgo. As variedades de sorgo (Sorghum bicolor L. Moench) utilizadas para a confecção das silagens de grãos úmido de sorgo (SGUS) foram BRS-700 (alto conteúdo de tanino) e DAS 741 (baixo conteúdo de tanino). A SGUS de alto conteúdo de tanino foi confeccionada na Faculdade de Medicina Veterinária e Zootecnia (UNESP), em Botucatu - SP, e ensiladas em tambores de polietileno com capacidade para 200 L. Nessa ocasião, os grãos apresentavam teor de umidade de $31,25 \%$. A variedade de sorgo de baixo conteúdo de tanino foi cultivada na Fazenda Experimental de Iguatemi (FEI-CCA/ UEM) e colhida com colhedeira mecânica quando os grãos apresentavam-se no estádio farináceo e com teor de umidade de $34,10 \%$. Os grãos foram triturados em moinho do tipo martelo com peneira de $6 \mathrm{~mm}$ e ensilados em manilhas de concreto com capacidade para $1.000 \mathrm{~L}$.

As silagens, tanto de alto quanto de baixo conteúdo de tanino, permaneceram armazenadas durante quatro meses, para o ensaio de digestibilidade, ou um ano, para o experimento de desempenho.

O ensaio de digestibilidade constou de dez dias, sendo cinco dias para adaptação às dietas experimentais e cinco para coleta das excretas, no qual se adotou o método tradicional de coleta total de excretas. Noventa pintos de corte Cobb, machos, de 20 a 30 dias de idade foram distribuídos em um delineamento inteiramente casualizado com três tratamentos, seis repetições e cinco aves por unidade experimental. As aves foram alojadas em gaiolas de arame galvanizado e receberam água e ração à vontade durante o dia, para evitar desperdício. 
Os tratamentos consistiram de uma ração-referência (RR) à base de milho e farelo de soja e de outras duas rações-teste, com 35\% (na MS) de silagem de grãos úmidos de sorgo de alto ou de baixo conteúdo de tanino em substituição à ração-referência (Tabela 1).

As rações foram pesadas e misturadas diariamente, sendo calculadas com base nas exigências nutricionais da linhagem e na composição química dos alimentos, de acordo com recomendações de Rostagno et al. (2000).

Após o período de adaptação, iniciou-se a coleta das excretas, utilizando-se óxido férrico ( $2 \%$ ) na ração como marcador do início e do final de coleta. Para evitar perda de materiais, as gaiolas foram forradas com plástico e as coletas foram realizadas a cada 12 horas, durante todo o período experimental.

As excretas foram acondicionadas em sacos plásticos, devidamente identificadas por repetição e armazenadas em congelador após cada coleta. No final do período experimental, foram determinadas as quantidades de ração consumida e de excretas produzidas por repetição. As excretas foram descongeladas, reunidas por parcela, homogeneizadas, pesadas e mantidas em estufa de ventilação forçada a $55^{\circ} \mathrm{C}$ por 72 horas. Após a pré-secagem, foram moídas e acondicionadas para análises dos teores de matéria seca, amido, matéria orgânica, proteína bruta e energia bruta.

As análises das rações e das excretas foram feitas segundo metodologias descritas por Silva \& Queiroz (2002).

As determinações de amido dos alimentos e das excretas foram obtidas pelo método enzimático proposto por Poore et al. (1989), adaptado por Pereira \& Rossi (1995). Os valores de $\mathrm{pH}$ das SGUS de alto e baixo conteúdo de tanino foram calculados pelo método utilizado por Phillip \& Fellner (1992).

Os teores de tanino dos grãos secos e úmidos antes da ensilagem e das silagens, após processo fermentativo, foram estimados de acordo com o Método Azul da Prússia, descrito por Magalhães et al. (2000).

Os valores de energia bruta das rações, dos alimentos e das excretas foram determinados utilizando-se calorímetro adiabático (Parr Instruments Co).

Os coeficientes de metabolização da matéria seca (CMMS), da proteína bruta (CMPB), do amido (CMAM), da matéria orgânica (CMMO) e da energia bruta (CMEB) dos alimentos testados foram submetidos à análise de variância.

Os teores de energia metabolizável aparente corrigida para balanço de nitrogênio da silagem de grãos úmidos de sorgo de alto ou baixo conteúdo de tanino foram calculados utilizando-se a fórmula de Matterson et al. (1965).
Tabela 1 - Composição percentual da ração-referência Table 1 - Ingredient composition of the reference diet (\%)

\begin{tabular}{lc}
\hline Ingrediente (Ingredient) & $\%$ \\
\hline Milho grão $^{1}$ (Corn grain) & 57,526 \\
Farelo de soja (Soybean meal) $^{\text {Óleo de soja (Soybean oil) }}$ & 36,610 \\
Fosfato bicálcico (Dicalcium phosphate) $_{\text {Calcário (Limestone) }}, 102$ \\
Sal comum (Salt) & 1,796 \\
DL-metionina (DL-Methionine) & 1,047 \\
L-lisina HCl (L-Lysine HCl) & 0,400 \\
Supl. mineral ${ }^{1}$ (Mineral supplement) & 0,207 \\
Supl. vitamínico ${ }^{1}$ (Vitamin supplement) & 0,102 \\
BHT (BHT) & 0,100 \\
TOTAL & 0,100 \\
\end{tabular}

Nutrientes - Composição calculada

Nutrients - Calculated composition

$\mathrm{EM}, \mathrm{kcal} / \mathrm{kg}(\mathrm{ME}, \mathrm{kcal} / \mathrm{kg}) \quad 3.000$

$\mathrm{PB}, \%(C P, \%) \quad 21,40$

Met + Cis total, \% (Total Met + Cys, \%) $\quad 0,897$

Lisina total, \% (Total lysine, \%) 1,263

Cálcio, \% (Calcium, \%) $\quad 0,960$

Fósforo disp. ${ }^{1}$, \% (Available phosphorus, \%) $\quad 0,450$

${ }^{1}$ Suplemento vitamínico e mineral. Composição por kg de produto: Vit. A - 2.000.000 UI; Vit. D - 320.000UI; Vit. E - 4.000 mg; Vit. K - 500 mg; Vit. B1 - 240 mg; Vit. B2 - 800 mg; Vit. B6 - 400 mg; Ac. fólico - 100 mg; Ác. nicotínico - 5.000 mg; Biotina - 16 mg; Ác. pantotênico - 2.100 mg; Colina - $60.000 \mathrm{mg}$; Vit. B12 - $2.000 \mathrm{mcg}$; Ferro - $10.000 \mathrm{mg}$; Cobre 1.600 mg; Manganes - 12.000 mg; Cobalto - 80 mg; Zinco -10.000 mg; lodo - 20 mg; Selênio - 40 mg; Antioxidante - 20.000 mg; Metionina 217.800 mg; Coccidiostático - 20.000 mg; Veículo q.s.p. - 1.000 g.

1 Mineral and vitamin supplement. Nutritional levels per kg of product: Vit. A-2.000.000 UI, Vit. D - 320.000UI, Vit. E - $4.000 \mathrm{mg}$, Vit. K- $500 \mathrm{mg}$, Vit. B1 - $240 \mathrm{mg}$, Vit. B2 - $800 \mathrm{mg}$, Vit. B6 - $400 \mathrm{mg}$, Folic acid $-100 \mathrm{mg}$, Nicotinic acid $-5.000 \mathrm{mg}$, Biotin - $16 \mathrm{mg}$, Panthotenic acid - $2.100 \mathrm{mg}$, Choline $-60.000 \mathrm{mg}$, Vit. B12 - $2.000 \mathrm{mcg}$, Iron - $10.000 \mathrm{mg}$, Copper $-1.600 \mathrm{mg}$, Manganese - $12.000 \mathrm{mg}$, Cobalt - $80 \mathrm{mg}$, Zinc - $10.000 \mathrm{mg}$; lodine $20 \mathrm{mg}$; Selenium - $40 \mathrm{mg}$, Antioxidant - $20.000 \mathrm{mg}$, Methionine - $217.800 \mathrm{mg}$, Coccidiostatic $-20.000 \mathrm{mg}$, vehicle q.s.p. $-1.000 \mathrm{~g}$

No experimento de desempenho, foram utilizados 840 pintos Cobb, machos, de um dia de idade, alojados em um galpão convencional dividido em boxes de $6,3 \mathrm{~m}^{2}$, com piso de concreto forrado com cama do tipo maravalha e paredes laterais de alvenaria, com $0,30 \mathrm{~m}$ de altura, completadas com tela de arame até o telhado e providas de cortinas laterais.

O delineamento experimental utilizado foi o inteiramente casualizado, com sete tratamentos, quatro repetições e 30 aves por unidade experimental.

$\mathrm{Na}$ fase inicial, até as aves atingirem sete dias de idade, foram utilizados comedouros do tipo bandeja e bebedouros tipo copo de pressão, substituídos gradativamente por comedouros tubulares e bebedouros automático pendulares. Os pintos foram mantidos em círculos de proteção sob uma campânula, como fonte de aquecimento. No sétimo dia de idade, as aves foram vacinadas contra Newcastle e Gumboro, via ocular.

O programa de alimentação foi dividido em três fases: inicial $($ do 10 ao 70 dia $)$ = foi fornecida somente a raçãoreferência; intermediária (do $8^{\circ}$ ao $21^{\circ}$ dia); e de crescimento (do $22^{\circ}$ ao $40^{\circ}$ dia $)$. 
As rações foram calculadas com base nas exigências nutricionais e na composição química dos alimentos, segundo Rostagno et al. (2000), e nos resultados de análises químicas, realizadas no Laboratório de Nutrição Animal da UEM/DZO.

Os tratamentos consistiram de uma ração-referência contendo milho seco e de outras seis, com 33, 66 e 100\% (na MS) de silagens de grãos úmidos de sorgo (SGUS) de alto ou baixo conteúdo de tanino, em substituição ao milho seco. As rações foram isoenergéticas, isocalóricas, isocálcicas, isofosfóricas e isoaminoacídicas para lisina e metionina + cistina.

Os ingredientes das rações, exceto as SGUS de alto e baixo conteúdo de tanino, foram previamente misturados. As SGUS de alto e baixo conteúdo de tanino foram incorporadas diariamente às respectivas rações nos níveis de 33, 66 e $100 \%$ de substituição ao milho seco. As rações foram pesadas diariamente e fornecidas na forma farelada. Todas as sobras das rações foram pesadas e descartadas 24 horas após o fornecimento.

As rações e os animais foram pesados a cada troca de rações, para o cálculo do ganho de peso, do consumo de ração e da conversão alimentar.

Antes do abate, procedeu-se à determinação da coloração da perna das aves, com auxílio de leque colorimétrico (Roche) com escala de 1 a 15 e, nos casos em que a cor esteve ainda mais clara, atribuiu-se o valor de 0,5.

Para verificar a viabilidade econômica da substituição do milho seco pelas SGUS nas rações, calculou-se inicialmente o custo de ração por quilograma de ganho de peso vivo, segundo Bellaver et al. (1985).
O consumo diário de ração (CDR), o ganho de peso (GP), a conversão alimentar (CA), a coloração da perna e as variáveis econômicas foram analisados utilizando-se o modelo estatístico que considerou o efeito da variedade de sorgo e o efeito do nível de substituição dentro de cada variedade de sorgo. Os graus de liberdade referentes aos níveis de substituição do milho seco pela SGUS de alto ou baixo conteúdo de tanino foram desdobrados em polinômios ortogonais.

Para comparação dos resultados obtidos entre a ração testemunha com cada um dos níveis de substituição dos sorgos testados, foi utilizado o teste de Dunnett a 5\%.

\section{Resultados e Discussão}

\section{Ensaio de digestibilidade}

Os teores de nutrientes, o pH e o diâmetro geométrico médio das SGUS são apresentados na Tabela 2. À exceção do fósforo total, a SGUS de baixo conteúdo de tanino apresentou valores nutricionais superiores aos da SGUS de alto teor de tanino, quando comparados na mesma base de matéria seca.

Entre os fatores de variação no valor nutricional das silagens, destacam-se o potencial genético da variedade, a adubação utilizada, as condições climáticas e a fertilidade do solo (Lima et al., 1998). Na tabela da EMBRAPA (1991), são descritos valores de 7,80 e 8,60\% de PB; 0,04 e $0,03 \%$ de $\mathrm{Ca} ; 0,25$ e $0,28 \%$ de Pt; e 3.855 e $3.982 \mathrm{kcal} / \mathrm{kg}$ de EB, respectivamente, para grãos de sorgo seco de alto e de baixo conteúdo de tanino, próximos aos determinados neste estudo, se comparados em mesma base de matéria seca.

Tabela 2 - Teores de nutrientes, valor de pH e diâmetro geométrico médio das partículas das silagens de grãos úmidos de sorgo (SGUS) ${ }^{1}$ de alto e baixo conteúdo de tanino, na matéria natural e em $87,45 \%$ de matéria seca

Tabela 2 - Contents of nutrients, $\mathrm{pH}$ value, and average geometric diameter of high moisture sorghum silage (HMSS) ${ }^{1}$ particles of high or low tannin contents, as-fed basis and $87.45 \%$ on dry matter basis

\begin{tabular}{|c|c|c|c|c|}
\hline \multirow[t]{2}{*}{$\begin{array}{l}\text { Parâmetro } \\
\text { Parameter }\end{array}$} & \multicolumn{2}{|c|}{$\begin{array}{l}\text { SGUS }^{2} \\
H M S S^{2}\end{array}$} & \multicolumn{2}{|c|}{$\begin{array}{l}\text { SGUS }^{3} \\
H M S S^{3}\end{array}$} \\
\hline & $\begin{array}{c}\text { Alto tanino } \\
\text { High tannin }\end{array}$ & $\begin{array}{c}\text { Baixo tanino } \\
\text { Low tannin }\end{array}$ & $\begin{array}{c}\text { Alto tanino } \\
\text { High tannin }\end{array}$ & $\begin{array}{c}\text { Baixo tanino } \\
\text { Low tannin }\end{array}$ \\
\hline Matéria seca, \% (Dry matter, \%) & 66,22 & 65,28 & 87,45 & 87,45 \\
\hline Proteína bruta, \% (Crude protein, \%) & 5,93 & 6,37 & 7,83 & 8,53 \\
\hline Amido, \% (Starch, \%) & 35,20 & 39,75 & 46,49 & 53,25 \\
\hline Matéria orgânica, \% (Organic matter, \%) & 65,10 & 64,29 & 85,97 & 86,12 \\
\hline Cinzas, \% (Ash, \%) & 1,07 & 1,08 & 1,41 & 1,45 \\
\hline Cálcio, \% (Calcium, \%) & 0,02 & 0,03 & 0,02 & 0,04 \\
\hline Fósforo total, \% (Total phosphorus, \%) & 0,19 & 0,14 & 0,25 & 0,19 \\
\hline Energia bruta, $\mathrm{kcal} / \mathrm{kg}$ (Gross energy, kcal/kg) & 2.912 & 2.894 & 3.845 & 3.877 \\
\hline $\mathrm{pH}$ & 4,55 & 4,32 & - & - \\
\hline Diâmetro geométrico médio, $\mu \mathrm{m}$ (Medium geometric diameter, $\mu \mathrm{m}$ ) & 571 & 678 & - & - \\
\hline
\end{tabular}

\footnotetext{
${ }^{1}$ Análises realizadas no Laboratório de nutrição animal (Analysis done at Animal Nutrition Laboratory).

2 Valores na matéria natural (As-fed basis).

${ }^{3}$ Valores convertidos para $87,45 \%$ de MS, conforme os dados constantes na tabela da EMBRAPA (1991) para o milho seco (grão) (Values converted for $87.45 \%$ of dry matter basis according to data table from EMBRAPA, 1991 for dry corn).
} 
Os valores de $\mathrm{pH}$ das silagens de sorgo de alto $(4,55)$ e baixo $(4,32)$ conteúdo de tanino podem ser considerados satisfatórios, uma vez que foram próximos ao verificado por Romero et al. (1996), de 4,2, em silagens de grãos úmidos de sorgo.

O sorgo de baixo teor de tanino (Tabela 3) apresentou de 0,44 a $0,69 \%$ de tanino/compostos fenólicos. Segundo Zardo \& Lima (1999), o sorgo com 0,60\% de tanino, analisado pelo Método Azul da Prússia, é considerado isento de tanino. Magalhães et al. (2000), por sua vez, afirmam que percentuais abaixo de $0,70 \%$ de polifenóis totais são decorrentes de outros fenóis, e não do tanino condensado; portanto, não são prejudiciais ao desempenho animal.

No sorgo de alto tanino, os teores de tanino variaram de 1,44\% (grãos secos antes do plantio) a 1,14\% (SGUS após o período fermentativo), redução de aproximadamente $20 \%$ do teor de tanino dos grãos, comprovando que o processo de ensilagem foi ineficiente para remover a maior parte do tanino presente no grão de sorgo. Segundo Mitaru et al. (1984b), no processo de reconstituição, que envolve a adição de água e subseqüente incubação anaeróbica a $25^{\circ} \mathrm{C}$, ocorre remoção de até $97 \%$ do tanino quimicamente detectável.

Os coeficientes de metabolização da matéria seca, matéria orgânica e da energia bruta diferiram $(\mathrm{P}<0,05)$ entre as silagens de grãos úmidos de sorgo de alto e baixo conteúdo de tanino e foram maiores para a de baixo conteúdo de tanino (Tabela 4).

O coeficiente de metabolização da proteína bruta, embora numericamente maior para a silagem de baixo conteúdo de tanino, não diferiu $(\mathrm{P}<0,05)$ da silagem com alto teor de tanino e pode ser explicado pelo menor conteúdo de tanino presente nos grãos.

Segundo Magalhães et al. (2000), o tanino presente em algumas variedades de sorgo pode causar problemas na digestão dos alimentos pelos animais, por formar complexos com proteínas, diminuindo a palatabilidade e a digestibilidade do alimento. De acordo com Halley et al.

Tabela 3 - Conteúdo de tanino/compostos fenólicos nos grãos secos, nos grãos úmidos e nas silagens de grãos úmidos de sorgo de alto e baixo teores de tanino

Table - Tannins/phenol compounds in corn grain, high moisture corn, and high moisture sorghum silage of high and low tannin contents

\begin{tabular}{lcc}
\hline $\begin{array}{l}\text { Parâmetro } \\
\text { Parameter }\end{array}$ & $\begin{array}{c}\text { Conteúdo de taninos (\%) } \\
\text { Tannin contents }\end{array}$ \\
\cline { 2 - 3 } & $\begin{array}{c}\text { Alto tanino } \\
\text { High tannin }\end{array}$ & $\begin{array}{c}\text { Baixo tanino } \\
\text { Low tannin }\end{array}$ \\
\hline Grão seco (Corn grain) & 1,44 & 0,44 \\
Grão úmido (High moisture corn) & 1,09 & 0,44 \\
Silagem (Silage) & 1,14 & 0,69
\end{tabular}

Tabela 4 - Coeficientes de metabolização de MS (CMMS), PB (CMPB), amido (CMAM), MO (CMMO) e energia bruta (CMEB) da silagens de grãos úmidos de sorgo (SGUS) de alto e baixo conteúdos de tanino

Table 4 - Metabolization coefficient of DM (DMMC), CP(CPMC), starch (SMC), OM (OMMC), and GE (GEMC) of high moisture sorghum silage (HMSS) grain of high or low tannin contents

\begin{tabular}{lccr}
\hline Parâmetro & \multicolumn{2}{c}{ SGUS } & CV (\%) \\
Parameter & HMSS & \\
\cline { 2 - 3 } & $\begin{array}{c}\text { Alto tanino } \\
\text { High tannin }\end{array}$ & $\begin{array}{c}\text { Baixo tanino } \\
\text { Low tannin }\end{array}$ \\
\hline CMMS, \% (DMMC, \%) & $86,51^{\mathrm{b}}$ & $92,56^{\mathrm{a}}$ & 3,32 \\
CMPB, \% (CPMC, \%) & 75,05 & 80,25 & 12,30 \\
CMAM, \% (SMC, \%) & 100,00 & 100,00 & 0,00 \\
CMMO, \% (OMMC, \%) & $87,48^{\mathrm{b}}$ & $93,24^{\mathrm{a}}$ & 2,59 \\
CMEB, \% (GEDM, \%) & $82,87^{\mathrm{b}}$ & $89,29^{\mathrm{a}}$ & 2,77 \\
\hline
\end{tabular}

Médias seguidas de letras distintas na mesma linha diferem $(P<0,05)$ pelo teste $\mathrm{F}$.

Means followed by different letters in the same row differ $(P<0.05)$ by F test.

(1986), o coeficiente de metabolização da energia bruta tende a diminuir com o aumento do conteúdo de tanino nas dietas, visto que o tanino pode formar complexos com carboidratos, reduzindo a atividade da enzima amilase e, conseqüentemente, o metabolismo, e diminuindo o aproveitamento energético do carboidrato. No entanto, conforme Ondarza (2000), os grãos ensilados com alta umidade aumentam a digestão do amido por meio da quebra da estrutura protéica dos grãos, desfazendo a estrutura cristalina do amido.

Para comparação dos dados com os de outros trabalhos, os teores de nutrientes digestíveis foram convertidos para $87,45 \%$ de matéria seca, com base na matéria seca do milho seco comum, de acordo com tabela da EMBRAPA (1991), como apresentado na Tabela 5.

A EMAn determinada para a SGUS de alto conteúdo de tanino foi de $3.180 \mathrm{kcal} / \mathrm{kg}$, semelhantes aos valores descritos pela EMBRAPA (1991) e por Rostagno (2000), de 3.163 e $3.010 \mathrm{kcal} / \mathrm{kg}$, respectivamente, enquanto a EMAn determinada para a SGUS com baixo conteúdo de tanino $(3.454 \mathrm{kcal} / \mathrm{kg}$ ) foi superior a esses valores.

Nunes et al. (2001) afirmam que o tanino condensado, além de afetar o valor nutricional dos alimentos, formando complexos com proteínas, íons metálicos divalentes, carboidratos e outras macromoléculas, também inibe a atividade de várias enzimas digestivas e provoca erosões das células epiteliais do intestino, diminuindo a absorção dos nutrientes através da parede intestinal.

Experimento de desempenho

No ensaio de desempenho, conforme dados apresentados na Tabela 6, excluindo a ração testemunha, a análise de regressão comprovou redução linear $(\mathrm{P}<0,05)$ no peso vivo 
Tabela 5 - Teores de matéria seca metabolizável (MSM), proteína metabolizável (PM), amido metabolizável (AMM), matéria orgânica metabolizável (MOM), e energia metabolizável aparente corrigida para retenção de nitrogênio (EMAn) das SGUS de alto e baixo conteúdos de tanino, na matéria natural e em $87,45 \%$ de MS

Table 5 - Content of metabolizable dry matter (MDM), metabolizable protein (MP), metabolizable starch (MS), metabolizable organic matter (OMM), and metabolizable energy corrected for nitrogen retention (AMEn) of high moisture sorghum silage (HMSS) ${ }^{1}$ as fed basis and in $87.45 \%$ of dry matter

\begin{tabular}{|c|c|c|c|c|}
\hline \multirow[t]{2}{*}{$\begin{array}{l}\text { Nutriente } \\
\text { Nutrient }\end{array}$} & \multicolumn{2}{|c|}{$\begin{array}{l}\text { SGUS }^{1} \\
\text { HMSS }^{l}\end{array}$} & \multicolumn{2}{|c|}{$\begin{array}{l}\text { SGUS }^{2} \\
\text { HMSS }^{2}\end{array}$} \\
\hline & $\begin{array}{l}\text { Alto tanino } \\
\text { High tannin }\end{array}$ & $\begin{array}{l}\text { Baixo tanino } \\
\text { Low tannin }\end{array}$ & $\begin{array}{l}\text { Alto tanino } \\
\text { High tannin }\end{array}$ & $\begin{array}{l}\text { Baixo tanino } \\
\text { Low tannin }\end{array}$ \\
\hline MSM, \% (MDM, \%) & 57,29 & 60,42 & 75,66 & 80,94 \\
\hline $\mathrm{PM}, \%(M P, \%)$ & 4,45 & 5,11 & 5,88 & 6,85 \\
\hline AMM, \% (MS, \%) & 35,27 & 39,58 & 46,58 & 53,02 \\
\hline MOM, \% (OMM, \%) & 56,96 & 59,95 & 75,22 & 80,31 \\
\hline EMAn, $\mathrm{kcal} / \mathrm{kg}(A M E n, \mathrm{kcal} / \mathrm{kg})$ & 2.408 & 2.578 & 3.180 & 3.454 \\
\hline
\end{tabular}

1 Valores na matéria natural.

${ }^{2}$ Valores convertidos para $87,45 \%$ de matéria seca (MS) conforme os dados apresentados pela tabela da EMBRAPA (1991) para o milho seco (grão).

1 Asfed basis values.

2 Values converted for $87.45 \%$ of dry matter (DM) basis according to data table presented by EMBRAPA (1991) for dry yellow corn (grain).

das aves aos 40 dias de idade, quando o milho foi substituído gradativamente pelas SGUS de baixo $(\hat{Y}=2,521329$ $\left.0,000989357 \mathrm{X} \mathrm{r}^{2}=0,84\right)$ ou de alto teor de tanino $\left(\hat{\mathrm{Y}}=2,700249-0,003632027 \mathrm{r}^{2}=1,00\right)$.

A inclusão de níveis crescentes de SGUS de alto conteúdo de tanino também promoveu redução linear $(\mathrm{P}<0,05)$ no ganho de peso aos 40 dias de idade.

Verificou-se, pelo teste de Dunnett $(\mathrm{P}<0,05)$, que as aves que receberam a ração com SGUS de alto conteúdo de tanino nos níveis de 66 e 100\% de substituição, apresentaram, aos 40 dias de idade, menores peso e ganho de peso que as aves alimentadas com a ração testemunha. O peso e ganho de peso aos 40 dias de idade não diferiram entre as aves alimentadas com a ração com SGUS de baixo tanino $(\mathrm{P}>0,05)$ e as que receberam ração com milho seco.
A redução linear observada no ganho de peso das aves, à medida que o milho foi substituído pelas SGUS, pode ser explicada pelo fato de o tanino presente nos grãos de sorgo afetar a palatabilidade e a digestibilidade dos nutrientes.

O consumo de ração das aves alimentadas com a ração contendo SGUS de alto teor de tanino ( $\hat{Y}=4,156593$ $\left.0,003460750 \mathrm{X} \mathrm{r}^{2}=0,99\right)$ reduziu linearmente $(\mathrm{P}<0,05)$ dos 7 aos 40 dias de idade, sendo menor $(\mathrm{P}<0,05)$ nos níveis de 66 e 100\% de substituição do milho pela silagem, como conseqüência da baixa palatabilidade das rações (sabor adstringente), que ocasiona rejeição pelas aves.

Verificou-se piora linear $(\mathrm{P}<0,05)$ na conversão alimentar das aves alimentadas com ração contendo níveis crescentes de substituição do milho pela SGUS de alto $\left(\hat{Y}=1,719635+0,01462971 X r^{2}=0,99\right)$ ou de baixo $\left(\hat{\mathrm{Y}}=1,781854+0,000547004 \mathrm{X} \mathrm{r}^{2}=0,97\right)$ conteúdo de tanino

Tabela 6 - Peso vivo, consumo de ração (CR), ganho de peso (GP) e conversão alimentar (CA) de frangos de corte alimentados com rações contendo níveis crescentes de substituição do milho seco por SGUS de alto ou baixo conteúdo de tanino no período de 7 a 40 dias

Table 6 - Body weight (BW), feed intake (FI), weight gain (WG), and feed:gain ratio (F:G) of broilers fed with diets with increasing corn grain replacement with HMSS of high or low tanin contents from 7 to 40 days

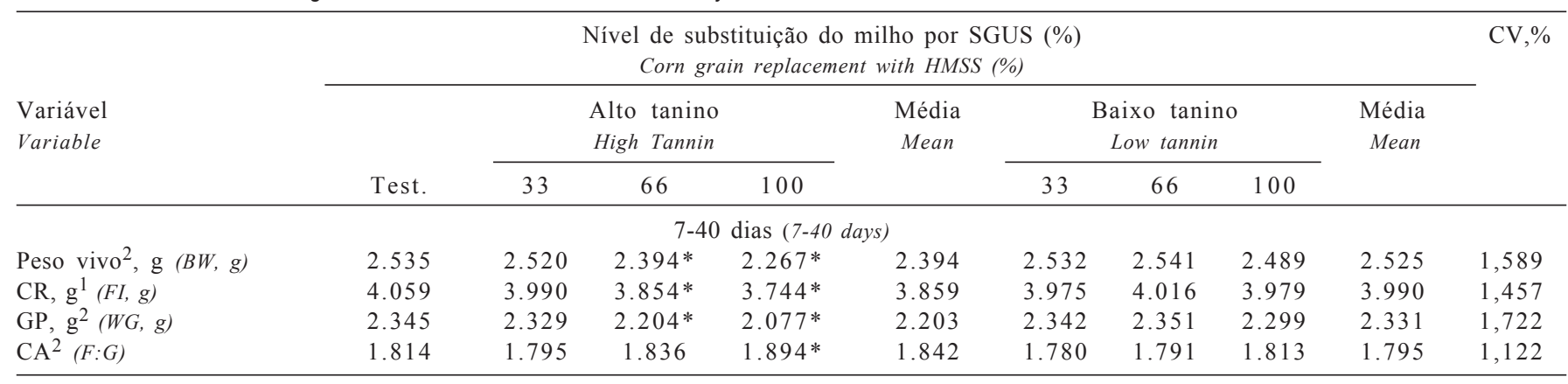

\footnotetext{
1 Efeito linear $(P<0,05)$ dos níveis de substituição do milho por SGUS de alto tanino

2 Efeito linear $(P<0,05)$ dos níveis de substituição do milho por SGUS de alto e baixo tanino

* Difere da ração testemunha pelo teste de Dunnett $(P<0,05)$.

1 Linear effect $(P<0.05)$ of corn replacement with HMSS of high tannin.

2 Linear effect $(P<0.05)$ of corn replacement with HMSS of high and low tannin contents.

* Differs from diet control by Dunnett test $(P<0.05)$.
} 
aos 40 dias de idade, porém, para a SGUS de baixo tanino, não houve diferença da CA dos níveis avaliados em relação à ração-teste.

A comparação pelo teste de Dunnett $(\mathrm{P}<0,05)$ da raçãoreferência com cada nível de inclusão das silagens demonstrou que a conversão alimentar aos 40 dias de idade foi pior $(\mathrm{P}<0,05)$ para as aves que receberam as dietas contendo a SGUS de alto tanino no nível de $100 \%$ de substituição ao milho, porém não diferiu $(\mathrm{P}>0,05)$ daquela verificada com a SGUS de baixo tanino e a ração-referência.

Queiroz et al. (1978) pesquisaram a substituição de 0, 50,75 e $100 \%$ do milho pelo sorgo de baixo e de alto teores de tanino em rações para frangos de corte de 1 a 18 dias de idade e verificaram que o ganho de peso não foi afetado quando o milho foi substituído em até $100 \%$ pelo sorgo de baixo tanino e em até $75 \%$ pelo sorgo de alto tanino. A conversão alimentar das aves que receberam a ração contendo milho, no entanto, foi melhor que a obtida com 50, 75 e $100 \%$ de substituição do milho pelos sorgos de alto e baixo teores de tanino.

Os prejuízos observados no desempenho das aves podem estar relacionados ao teor de tanino das rações, uma vez que a ensilagem não foi eficiente para remover grande parte do tanino presente no sorgo. A redução de apenas $20 \%$ do tanino durante o processo de ensilagem foi ineficiente para amenizar seus efeitos sobre o desempenho dos frangos de corte.

Segundo Rostagno (1986), o tanino presente no grão de sorgo influencia negativamente a disponibilidade de aminoácidos do sorgo, prejudicando o desempenho dos animais. Além disso, Teeter et al. (1986) constataram, por meio de desintoxicação, remoção de $100 \%$ do tanino quimicamente detectável em grãos de sorgo de alto conteúdo de tanino, promovendo melhorias na taxa de crescimento e na eficiência alimentar de frangos de corte. Contudo, esses benefícios não foram evidenciados no mesmo processo aplicado aos grãos de sorgo de baixo tanino.
A pigmentação da pele de frangos de corte é de grande importância comercial, visto que carcaças com melhor pigmentação apresentam maior aceitação pelo consumidor. Um dos fatores limitantes da utilização do sorgo em rações para frangos de corte é o baixo nível de pigmentos xantófilos quando comparados ao milho.

Níveis crescentes de substituição do milho pelas SGUS, de alto $\left(\hat{Y}=3,672492-0,02576849 \mathrm{X} \mathrm{r}^{2}=0,99\right)$ e de baixo $\left(\hat{\mathrm{Y}}=3,795705-0,02801455 \mathrm{X} \mathrm{r}^{2}=0,99\right)$ conteúdos de tanino promoveram decréscimo linear $(\mathrm{P}<0,05)$ na coloração da perna das aves (Tabela 7). Segundo Bellaver (2003), o sorgo pode consistir em excelente alternativa na alimentação de aves, desde que incluídos ingredientes com pigmentos carotenóides ou xantofílicos.

O custo da ração (Tabela 8) por quilograma de ganho de peso vivo (CR) de frangos de corte dos 7 aos 21 $\left(\hat{Y}=0,677908-0,000590180 \mathrm{X} \mathrm{r}^{2}=0,99\right)$ e dos 21 aos 40 $\left(\hat{Y}=0,880517-0,000923132 \mathrm{Xr}^{2}=0,99\right)$ dias de idade alimentados com SGUS de baixo conteúdo de tanino reduziu linearmente $(\mathrm{P}<0,05)$ com o aumento dos níveis de substituição do milho pela SGUS. Para a SGUS de alto conteúdo de tanino, não foram observadas diferenças $(\mathrm{P}>0,05)$ para os diferentes níveis de inclusão.

Os melhores IEE e IC foram obtidos quando a SGUS de baixo conteúdo de tanino substituiu em $100 \%$ o milho comum das rações.

Verificou-se, pelo teste de Dunnett $(\mathrm{P}<0,05)$, que o custo da ração, dos 7 aos 21 dias, por quilograma de ganho de peso vivo de frangos de corte foi menor $(\mathrm{P}<0,05)$ para a ração contendo a SGUS de baixo teor de tanino no nível de $100 \%$ de substituição. O custo da ração com SGUS de alto conteúdo de tanino por quilograma de ganho de peso vivo, não diferiu da ração-referência dos 7 aos 21 dias de idade.

As rações de crescimento, fornecidas dos 21 aos 40 dias, contendo a SGUS de baixo tanino apresentaram menor custo $(\mathrm{P}<0,05)$ por quilograma de peso vivo, quando comparadas à ração-referência, pelo teste Dunnett $(\mathrm{P}<0,05)$.

Tabela 7 - Coloração da perna de frangos de corte alimentados com rações contendo níveis crescentes de substituição do milho seco por SGUS de alto ou baixo conteúdos de tanino

Table 7 - Shank color of broilers fed diets containing increasing corn grain replacement with HMSS of high or low tanin contents

\begin{tabular}{|c|c|c|c|c|c|c|c|c|}
\hline \multirow{3}{*}{$\begin{array}{l}\text { Variável } \\
\text { Variable }\end{array}$} & \multirow[t]{3}{*}{$\begin{array}{l}\text { Ração-referência } \\
\text { Control diet }\end{array}$} & \multicolumn{6}{|c|}{$\begin{array}{l}\text { Nível de substituição do milho seco por SGUS, \% } \\
\text { Replacement levels of normal dry corn for HMSS, \% }\end{array}$} & \multirow{3}{*}{$\mathrm{CV}, \%$} \\
\hline & & \multicolumn{3}{|c|}{$\begin{array}{l}\text { Alto tanino } \\
\text { High tannin }\end{array}$} & \multicolumn{3}{|c|}{$\begin{array}{l}\text { Baixo tanino } \\
\text { Low tannin }\end{array}$} & \\
\hline & & 33 & 66 & 100 & 33 & 66 & 100 & \\
\hline $\begin{array}{l}\text { Coloração da canela }{ }^{1} \\
\text { Shank color }\end{array}$ & 4,375 & $2,725^{*}$ & $2,025^{*}$ & $1,000^{*}$ & $2,825^{*}$ & $2,100 *$ & $0,950 *$ & 30,315 \\
\hline
\end{tabular}

1 Efeito linear $(P<0,05)$ dos níveis de substituição.

* Difere da ração testemunha pelo teste de Dunnett $(P<0,05)$.

${ }^{1}$ Linear effect $(P<0.05)$ of replacement levels for HMSS of high and low tannin.

${ }^{*}$ Differs from diet control by Dunnett test $(P<0.05)$. 
Tabela 8 - Custo do quilograma de ração, custo de ração por quilograma de ganho de peso vivo (CR) de frangos de corte, índice de eficiência econômica (IEE) e índice de custo (IC) nos períodos de 7 a 21 e de 21 a 40 dias

Table 8 - Diet cost per $\mathrm{kg}$, diet cost per $\mathrm{kg}$ of $B W(D C)$, profitability index (OI), and cost index (Cl) in the periods from 7 to 21 and 21 from to 40 days

$$
\begin{gathered}
\begin{array}{c}
\text { Ração-referência } \\
\text { Control }
\end{array} \\
\text { Nível de substituição do milho seco por SGUS, \% } \\
\text { Corn grain replacement with HMSS, \% }
\end{gathered}
$$

\begin{tabular}{|c|c|c|c|c|c|c|c|c|}
\hline \multirow[b]{2}{*}{$\begin{array}{l}\text { Custo da ração }{ }^{1}, \mathrm{R} \$ / \mathrm{kg} \\
\text { Diet cost, } R \$ / \mathrm{kg}\end{array}$} & \multicolumn{7}{|c|}{$7-21$ dias $(7-21$ days $)$} & \\
\hline & 0,469 & 0,464 & 0,459 & 0,454 & 0,457 & 0,434 & 0,416 & - \\
\hline $\begin{array}{l}\mathrm{CR}^{2}, \mathrm{R} \$ / \mathrm{kg} \text { PV ganho } \\
D C^{2}, R \$ / \mathrm{kg} B W \text { gain }\end{array}$ & 0,649 & 0,652 & 0,653 & 0,687 & 0,634 & 0,611 & $0,595 *$ & 3,402 \\
\hline IEE & 96,943 & 98,587 & 92,076 & 85,840 & 98,562 & 99,320 & 100 & - \\
\hline $\begin{array}{l}P I \\
\text { IC }\end{array}$ & 103,15 & 101,43 & 108,60 & 116,49 & 101,45 & 100,68 & 100 & - \\
\hline
\end{tabular}

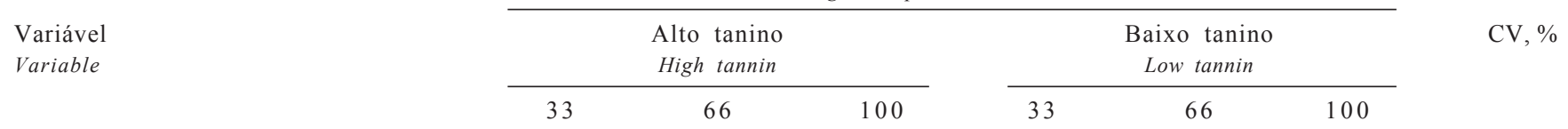

CI

\begin{tabular}{|c|c|c|c|c|c|c|c|c|}
\hline $\begin{array}{l}\text { Custo da ração }{ }^{1}, \mathrm{R} \$ / \mathrm{kg} \\
\text { Diet cost, } R \$ / \mathrm{kg}\end{array}$ & 0,462 & 0,456 & 0,451 & 0,445 & 0,442 & 0,423 & 0,404 & - \\
\hline $\begin{array}{l}\mathrm{CR}^{3}, \mathrm{R} \$ / \mathrm{kg} \text { PV ganho } \\
D C^{3}, R \$ / \mathrm{kg} B W \text { gain }\end{array}$ & 0,879 & 0,844 & 0,862 & 0,863 & $0,814^{*}$ & $0,779 *$ & $0,753 *$ & 2,543 \\
\hline IEE & 94,100 & 93,390 & 89,507 & 87,348 & 96,898 & 98,993 & 100 & - \\
\hline$E E R$ & & & & & & & & \\
\hline IC & 106,26 & 107,07 & 111,72 & 114,48 & 103,20 & 101,01 & 100 & - \\
\hline
\end{tabular}

$21-40$ dias $(21-40$ days $)$

$C R$

1 Custos baseados em uma relação de preços para a SGUS de $72 \%$ do valor (R\$) do milho seco comum.

2 Custo da ração por kg de PV ganho no período, efeito linear $(P<0,05)$, para os níveis de substituição da SGUS de baixo conteúdo de tanino $(\hat{Y}=0,677908$

${ }_{3}^{3}$ Custo da ração por kg de PV ganho no período, efeito linear $(P<0,05)$, para os níveis de substituição da SGUS de baixo conteúdo de tanino $(\hat{Y}=0,880517$ $-0,000923132 X)$.

* Difere da ração-referência pelo teste Dunnett $(P<0,05)$.

1 Costs based on prices relation for HMSS of $72 \%(R \$)$ of corn grain value.

2 Diet cost per $k g$ of BW gain in the period, linear effect $(P<0.05)$, for the corn replacement with HMSS of low tannin $(Y=0,677908-0,000590180 X)$.

${ }^{3}$ Diet cost per kg of BW gain in the period, linear effect $(P<0.05)$, for the corn replacement with HMSS of tannin $(Y=0,880517-0,000923132 X)$.

${ }^{*}$ Differs from control by Dunnett test $(P<0.05)$.

\section{Conclusões}

As silagens de grãos úmidos de sorgo de alto e de baixo conteúdos de tanino apresentaram bons valores nutritivos, com 2.408 e $2.578 \mathrm{kcal} / \mathrm{kg}$ de energia metabolizável aparente corrigida para balanço de nitrogênio na matéria natural, respectivamente.

A substituição de $100 \%$ do milho pela silagem de grãos úmidos de sorgo de baixo conteúdo de tanino em rações para frangos de corte não prejudicou o desempenho e reduziu o custo por quilo produzido.

A silagem de grãos úmidos de sorgo de alto tanino pode substituir o milho em até $33 \%$, sem afetar o desempenho dos frangos de corte.

\section{Literatura Citada}

BELLAVER, C. 2003. Sistemas de produção de frangos de corte. Disponível: em: http://sistemasdeproducao.cnptia.embrapa.br Acesso em: 15/11/2003.

BELLAVER, C.; FIALHO, ET.; PROTAS, J.F.S. et al. Radícula de malte na alimentação de suínos em crescimento e terminação. Pesquisa Agropecuária Brasileira, v.20, n.8, p.969-974, 1985.

CARRIJO, A.S.; MERLOTO, H.K.; AMARAL, A.N. Silagem de grãos de milho na alimentação de frangos de corte. Desempenho e rendimento de carcaça. In: CONFERÊNCIA APINCO DE CIÊNCIA E TECNOLOGIA AVÍCOLAS, 2000, Campinas. Anais... Campinas: Fundação de Apinco de Ciência e Tecnologia Avícolas, 2000. p.50.

COSTA, C.; ARRIGONI, M.B.; SILVEIRA, A.C.; CHARDULO, L. A.L. Silagem de grãos úmidos. In: SIMPÓSIO SOBRE NUTRIÇÃO DE BOVINOS, 7., 1999, Piracicaba. Anais... Piracicaba: Fundação de Estudos Agrários Luiz de Queiroz, 1999. p.69-87.

EMPRESA BRASILEIRA DE PESQUISA AGROPECUÁRIA EMBRAPA. Tabela de composição química e valores energéticos de alimentos para suínos e aves. 3.ed. Concórdia: Embrapa Suínos e Aves, 1991. 97p.

GARCIA, D.C.; MAIER, J.C. Redução do teor de tanino no sorgo mediante moagem e armazenamento dos grãos e sua ação sobre o desempenho de pintos na fase inicial. Revista da Sociedade Brasileira de Zootecnia, v.24, n.1, p.70-77, 1995.

HALLEY, J.T.; NELSON, T.S.; KIRB, L.K. et al. The effect of tannin content of sorghum grain in poultry rations on dry matter digestion and energy utilization. Arkansas Farm Research, v. 35, n. 2, p. 8,1986

LIMA, G.J.M.M.; SOUZA, O.W.; BELLAVER, C. et a1. Determinação da composição química e do valor energético de silagem de grãos úmidos de milho para suínos. In: CONGRESSO NACIONAL DE MILHO E SORGO, 22., 1998, Recife. Anais... Recife: ABMS, 1998. p.277. 
MAGALHÃES, P.C.; RODRIGUES, W.A.; DURÃES, F.O.M. Tanino no grão de sorgo: bases fisiológicas e métodos de determinação. Sete Lagoas: Centro Nacional de Pesquisa de Milho e Sorgo EMBRAPA, 2000. 13p (Circular Técnica, 27).

MARTINS, C.L.; CRUZ, V.C.; PINHEIRO, D.F. Silagem de grãos úmidos de milho na alimentação de frangos de corte. Peso dos órgãos e morfometria intestinal. In: CONFERÊNCIA APINCO DE CIÊNCIA E TECNOLOGIA AVÍCOLAS, 2000, Campinas. Anais... Campinas: Fundação de Apinco de Ciência e Tecnologia Avícolas, 2000. p.49.

MATTERSON, L.D.; POTTER, L.M.; STUTZ, M.W. et al. The metabolizable energy of feed ingredients for chickens. Research Report, v.7, n.1, p.11-14, 1965.

MITARU, B.N.; REICHERT, R.D.; BLAIR, R. Nutritive value of reconstituted sorghum grains for weanling pigs. Journal of Animal Science, v.58, n.5, p.1211-1215, 1984a.

MITARU, B.N.; REICHERT, R.D.; BLAIR, R. The binding of dietary protein by sorghum tannins in the digestive tract of pigs. The Journal of Nutrition, v.114, n.10, p.1787-1796, 1984b.

NUNES, R.V.; BUTERI, C.B.; NUNES, C.G.V. et al. Fatores antinutricionais dos ingredientes destinados à alimentação animal. In: SIMPÓSIO SOBRE INGREDIENTES NA ALIMENTAÇÃO ANIMAL, 2001, Campinas. Anais... Campinas: 2001. p.246-272.

ONDARZA, B.M. 2000. Starch digestibility. [S.I.:Sn]. Disponível em: http://www.farme.com Acesso em: 25/09/2003.

PARR INSTRUMENTS Co., Moline, ie. Instructions for the 1241 and 1242 adiabatic calorimeters. Moline, 1984. 29p. (Parr Manual, 153).

PEREIRA, J.R.A.; ROSSI, J.R.P. Manual prático da avaliação nutricional dos alimentos. Piracicaba: Fundação de Estudos Agrários Luiz de Queiroz, 1995. 25p.

PHILLIP, L.E.; FELLNER, V. Effects of bacterial inoculation of high moisture ear corn on its aerobic stability, digestion and utilization for growth by beef steers. Journal of Animal Science, v.70, p.3178-3187, 1992.

POORE, J.R.; ECK, T.P.; SWINGLE, R.S. et al. Total starch and relative starch availability of grains. In: BIENAL CONFERENCE ON RUMEN fUnCtion, 20., 1989, Chicago. Proceedings... Chicago: 1989. p.35.
QUEIROZ, A.C.; ROSTAGNO, H.S.; SILVA, M.A. et al. Sorgos com diferentes conteúdos de tanino como substituto do milho para aves. Revista Ceres, v.25, n.139, p.234-241, 1978.

ROMERO, L.A.; DIAZ, M.C.; BRUNO, O.A. et al. Silaje de grano húmedo de maiz y sorgo en la alimentación de vacas lecheras. Rafaela: INTA, EEA, 1996. 22p (Informe Técnico, 110).

ROSTAGNO, H.S. Utilização do sorgo nas rações de aves e suínos. Informe Agropecuário, v.12, n.144, p.18-27, 1986.

ROSTAGNO, H.S.; ALBINO, L.F.T.; DONZELE, J.L. et al. Tabelas brasileiras para aves e suínos: composição de alimentos e exigências nutricionais. 1.ed. Viçosa, MG: Universidade Federal de Viçosa, 2000. 141p.

SARTORI, J.R.; COSTA, C.; PEZZATO, A.C. et al. Silagem de grãos úmidos de milho na alimentação de frangos de corte. Pesquisa Agropecuária Brasileira, v.37, n.7, p.1009-1015, 2002.

SCHEUERMANN, G.N. Utilização do sorgo em rações para frangos de corte. Sete Lagoas: Embrapa Milho e Sorgo, 1998. $3 p$ (Instrução Técnica, 9).

SILVA, D.J. QUEIROZ, J.S. Análise de alimentos (Métodos químicos e biológicos). 2.ed. Viçosa, MG: Universidade Federal de Viçosa, 2002. 235p.

TEETER, R.G.; SARANI, S.; SMITH, M.O. et al. Detoxification of high tannin sorghum grains. Poultry Science, v.65, n.1, p.6771,1986

Van SOEST, P.J. Nutritional ecology of the ruminant. 2.ed. Cornell: Cornell University Press, 1994. 476p.

ZARDO, A.O.; LIMA, G.J.M.M. Alimentos para suínos. Concórdia: Embrapa Suínos e Aves e EMATER RS, 1999. 80p (Boletim Informativo). 